\title{
Optimized production profile using a coupled reservoir-network model
}

\author{
A. Hoffmann ${ }^{1}$ (1) $\cdot$ Milan Stanko $^{2} \cdot$ Diana González $^{2}$
}

Received: 13 November 2018 / Accepted: 9 January 2019 / Published online: 24 January 2019

(c) The Author(s) 2019

\begin{abstract}
This paper presents an integrated approach for scheduling and forecasting oil and gas production by integrating models of the entire value chain, from the reservoirs to the sales points. The methodology ensures maximum oil production at each time step of the reservoir simulator while honoring all operational constraints of the system. The proposed method is applied to a small North Sea offshore field consisting of two oil reservoirs with API gravities of 37 and 39. 3 gas-lifted wells are producing in each reservoir. They are arranged in a production network connected to a surface process. Control variables include individual well choke opening (early stage) and gas lift injection rate (later stage). The system is subject to numerous operational constraints (e.g., maximum field liquid production, maximum gas lift injection rate). The proposed solution is built in a commercial IAM platform that connects the models and orchestrates the software execution and optimization. The optimization problem is formulated as a Mixed Integer Linear Program. The well and flowline performance curves are approximated with piecewise linear functions. Results show that such an integrated approach can significantly affect the production profile (up to 15\% difference against traditional "silo" approach). The proposed integrated solution is two-to-three times faster than traditional non-linear optimization methods, guarantees convergence towards the global maximum and it represents with an appropriate level of accuracy the original black-box model. This allows to run a lot of different scenarios making it a suitable tool for field development and planning optimization. The proposed method is used to optimize the field design and schedule. Optimal surface capacities are determined by brute force exploration of net present value function.
\end{abstract}

Keywords Production forecast · Field development and planning · Artificial lift · Optimization · Mixed Integer Linear Programming (MILP)

\section{List of symbols}

$\Delta N_{\mathrm{p}} \quad$ Incremental oil production (stb)

$\Delta t \quad$ Reservoir time step (day or months)

$E_{\text {cap }} \quad$ Capital expenditure (USD)

$E_{\text {op }} \quad$ Operating expenditure (USD)

$f_{\mathrm{w}} \quad$ Water cut $(\%)$

$i \quad$ Interest rate (\%)

$J \quad$ Well productivity index (stb/day/psi)

$N_{\text {years }} \quad$ Duration of the operator license (years)
$P_{\mathrm{o}} \quad$ Price of oil (USD/stb)

$p_{\mathrm{R}} \quad$ Reservoir pressure (psi)

$R_{\mathrm{p}} \quad$ Gas oil ratio (scf/stb)

$R_{y} \quad$ Revenue of year $y$ (USD)

$S_{\pi} \quad$ Saturation of phase $\pi \in\{o, g, w\}(\%)$

$V_{\mathrm{oy}} \quad$ Volume of oil produced during year $y(\mathrm{stb})$

GOR Gas oil ratio (scf/stb)

ID Inner diameter

IPR Inflow performance relationship

MD Measured depth (ft)

MILP Mixed Integer Linear Programming

NPV Net present value (USD)

SOS2 Special ordered set of type 2

SQP Sequential Quadratic Programming

TVD True vertical depth (ft)

WC Water cut (\%)

Diana González

diana.rengifo@ntnu.no

1 Tieto Oil and Gas, Paris, France

2 NTNU, Trondheim, Norway 


\section{Introduction}

The forecasting of oil and gas production rates is a critical activity typically performed during the field development stage and when the field is already producing. In the field development phase, revenue streams are calculated from the hydrocarbon production rates and are further used in economic evaluations [e.g., net present value (NPV)] of relevant development alternatives (Jahn et al. 2008).

Production scheduling consists of defining the production rates of wells and field with time (production profiles). Although to produce as much as possible as early as possible would appear to be the best alternative to early mitigate the development expenses, this is not always true (Haldorsen 1996). Higher production flow rates require bigger processing capacities of production fluids (oil, gas, and water) and injection (e.g., gas injection, water injection, etc.). Bigger processing capacities translate into higher capital expenditures (due to the increase in size and weight of the processing equipment) that might reduce the NPV of the project. This is especially relevant for standalone offshore developments, where capacity of topside facilities directly affect the design, size, and cost of the supporting structures such as platforms and floating vessels.

There are other problems that high production rates could potentially cause in the reservoir, e.g., gas and water coning or cusping, excessive sand production, etc. These problems reduce the ultimate recovery factor of the field, affecting negatively the project value.

Production profiles are usually the result of an iterative process between several disciplines within the company. Initial profiles are generated using reservoir models and taking into consideration factors like drainage area, recovery factor, well productivity, well placement, gas or water coning and sand production, among others. The reservoir models employed have none or very simple models for pressure drop in wells and surface network. Production rates are then validated or corrected by production engineers to account for the pressure drop in wells, artificial lift design, surface network, among others. Facilities engineers perform a pre-design of the processing system, map the requirements and operational constraints. The corrections and modifications are communicated back to the custodian of the reservoir model and the process is repeated.

This procedure is usually labor intensive, time consuming, and performed manually; therefore, it does not normally allow for an exhaustive evaluation of all development alternatives nor a probabilistic and robust assessment of uncertainty. This often leads to unoptimized production scenarios, lower revenues, and suboptimal decision making.

The use of integrated models (i.e., reservoir, wells, network, and facilities) is an alternative to obtain more realistic production profiles. However, it is not easy to implement, primarily because models are built in different tools or simulators, the custodians of the models are usually in separate business units, and the layout and characteristics of the production system are not defined in early development stages. Another important challenge is that the subsurface uncertainty is usually very high.

Coupling of reservoir and surface network models is a topic that has been researched extensively in the past. Barroux et al. (2000) presents a comprehensive review of commonly used coupling methods and approaches and their advantages and disadvantages. This study and others (e.g., Al-Shaalan et al. 2002) also discuss that coupled models provide in general production profiles that are more realistic than those obtained using standalone reservoir simulators. This is especially important in cases, where the back-pressure on the well sand face is significant (e.g., deep offshore projects) or where there is a complex surface network.

Coupling these models, however, can be time consuming and challenging. Some examples of integration are given by Dempsey et al. (1971), Fang and Lo (1996), Hepguler et al. (1997), and Valbuena et al. (2015). Some of the challenges are due to the complexity and non-linearity of the fundamental equations used to describe flow in porous media and in pipes and equipment and the solving strategies employed in each model. Explicit integration strategies limit the exchange of data between the models to a minimum and require fewer modifications to the individual solving algorithms. However, these strategies often exhibit stability problems and oscillations in the solutions (see Zapata et al. 2001). Implicit integration strategies are stable but require significant data transfer and modifications in the solving algorithms of the models thus making them more difficult to maintain and upgrade in the future.

Several papers address the issue of surface network optimization within the coupled model, see Hepguler et al. (1997) and Stanko and Venstad (2016). One recurring issue with network optimization lies in the combination of strongly non-linear behavior (well and flowline performances) and integer variables (routing or disjunctive constraints). When coupled with a reservoir simulation, additional constraints appear with runtime and stability, the network optimization being run at each time step with different reservoir conditions (reservoir pressure, GOR, WC).

In this paper, this issue was addressed using an MILP formulation of the network optimization problem. The non-linear well and flowline performances are approximated using SOS2 piecewise linear models. This approach is similar to what other authors have presented in the past, e.g., Codas et al. (2012), Codas and Camponogara (2012), Silva and Camponogara (2014), Hulse and Camponogara (2017), and Silva et al. (2015). Hoffmann et al. (2016) successfully apply this technique to optimize downhole diluent injection for an 
offshore heavy oil field and forecast field production. The work of Kosmidis et al. (2004) is the first one to employ piecewise linear approximations for non-linear functions in the petroleum engineering production problem. Piecewise linear tables are generated using sequentially the existing black-box model for different flow conditions. The formulation of the optimization problem takes considerably more effort and time to set up, but the running time is considerably lower than the traditional non-linear approach. The other advantage lies in the robust handling of integer variables.

This paper proposes an integrated methodology to schedule and forecast production. The approach integrates all elements of the production chain (wells, network and process) into a single integrated model to predict, within a single run, an optimized production profile that (1) honors all constraints throughout the production system and (2) ensures the highest production at each time step. The integrated model can then be used to assess the economical feasibility of different development alternatives.

The proposed methodology is applied on a scaled-down synthetic case consisting of six wells producing from two different reservoirs. The wells are producing into a common surface network and surface process, as shown in Fig. 1. Operational constraints considered are: (1) maximum water production; (2) maximum gas production; (3) maximum gas lift injection; and (4) maximum well pressure drawdown. Reservoirs are modeled using material balance (providing reservoir pressure, GOR and WC predictions for each well) and individual wells have inflow performance relationships (IPR) to represent the deliverability of the reservoir. The material balance is a rather simplistic analysis approach when compared against 3D reservoir simulation. However, it might still be applicable and valid for some cases (as discussed by Ali and Nielsen 1970) or at early stages of the

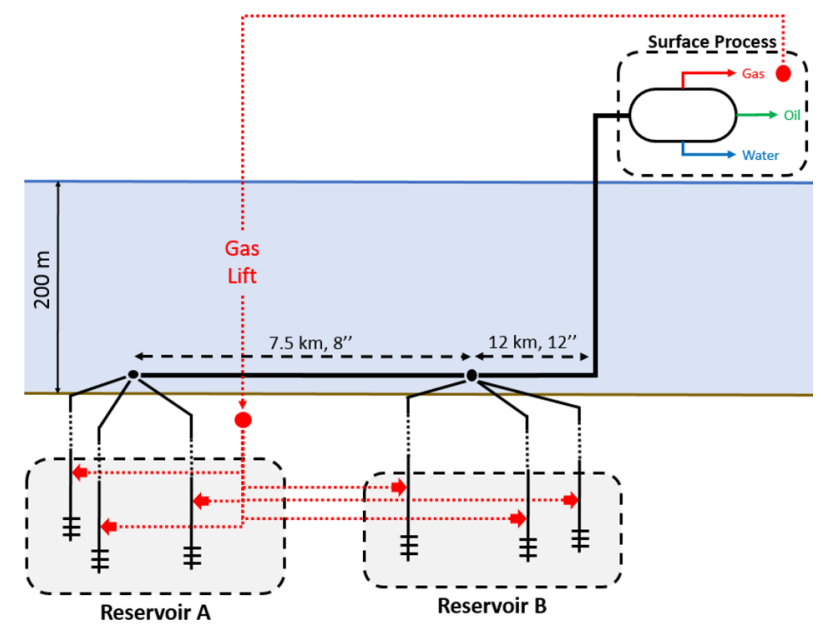

Fig. 1 Production system used in this paper field planning process, where the available information does not allow to build a more complex model.

\section{Production system modeling and optimization}

\section{Coupling strategy}

The proposed coupling strategy is presented in Fig. 2. In any given time step $t_{i}$, reservoir pressure $p_{\mathrm{R}_{i}}$, producing water cut (WC) $f_{\mathrm{w}_{i}}$ and gas oil ratio (GOR) $R_{\mathrm{p}_{i}}$ are transferred to the surface network model as well-boundary conditions. The network model is optimized, and the optimal well rates, choke openings, and gas lift rates are found. The cumulative production for step $t_{i}$ is found by summing the rate of all wells and multiplying by the length of the time step $\Delta t$. The incremental oil production $\Delta N_{\mathrm{p}}$, the reservoir conditions of the previous time step ( $p_{\mathrm{R}_{i}}$ and gas, oil, and water saturations: $\left.S_{\mathrm{g}_{i}}, S_{\mathrm{o}_{i}}, S_{\mathrm{w}_{i}}\right)$ and the material balance model are used to calculate reservoir pressure and producing WC and GOR of step $t_{i+1}$. The process is repeated.

The coupling strategy is explicit, meaning that the cumulative oil production for a given time step is calculated only once by assuming that the production rates calculated in time step $t_{i}$ are constant in the interval $t_{i}$ to $t_{i+1}$. This assumption is acceptable for small time steps $\Delta t$ (e.g., 1 month).

\section{Description of the base case}

The field studied in this paper is a small offshore field located in the North Sea.

\section{Reservoir models}

The characteristics of the reservoirs are given in Table 1 . Both reservoirs are modeled in a commercial material balance application. More details are provided in Appendix A.

\section{Well performance model}

A simple IPR model is used for each well. Above the bubble point, a straight line IPR is used, while the Vogel IPR is used below the bubble point.

Constraints on the reservoir pressure drawdown are applied to avoid sand production:

$p_{\bar{R}}^{j}-p_{\mathrm{wf}}^{j} \leq \Delta p_{\max }^{j}$,

where $p_{\bar{R}}^{j}, p_{\mathrm{wf}}^{j}$ and $\Delta p_{\max }^{j}$ are, respectively, the average drainage volume pressure, the bottom-hole pressure and the maximum pressure drawdown of well $j$. 
Fig. 2 Proposed coupling workflow

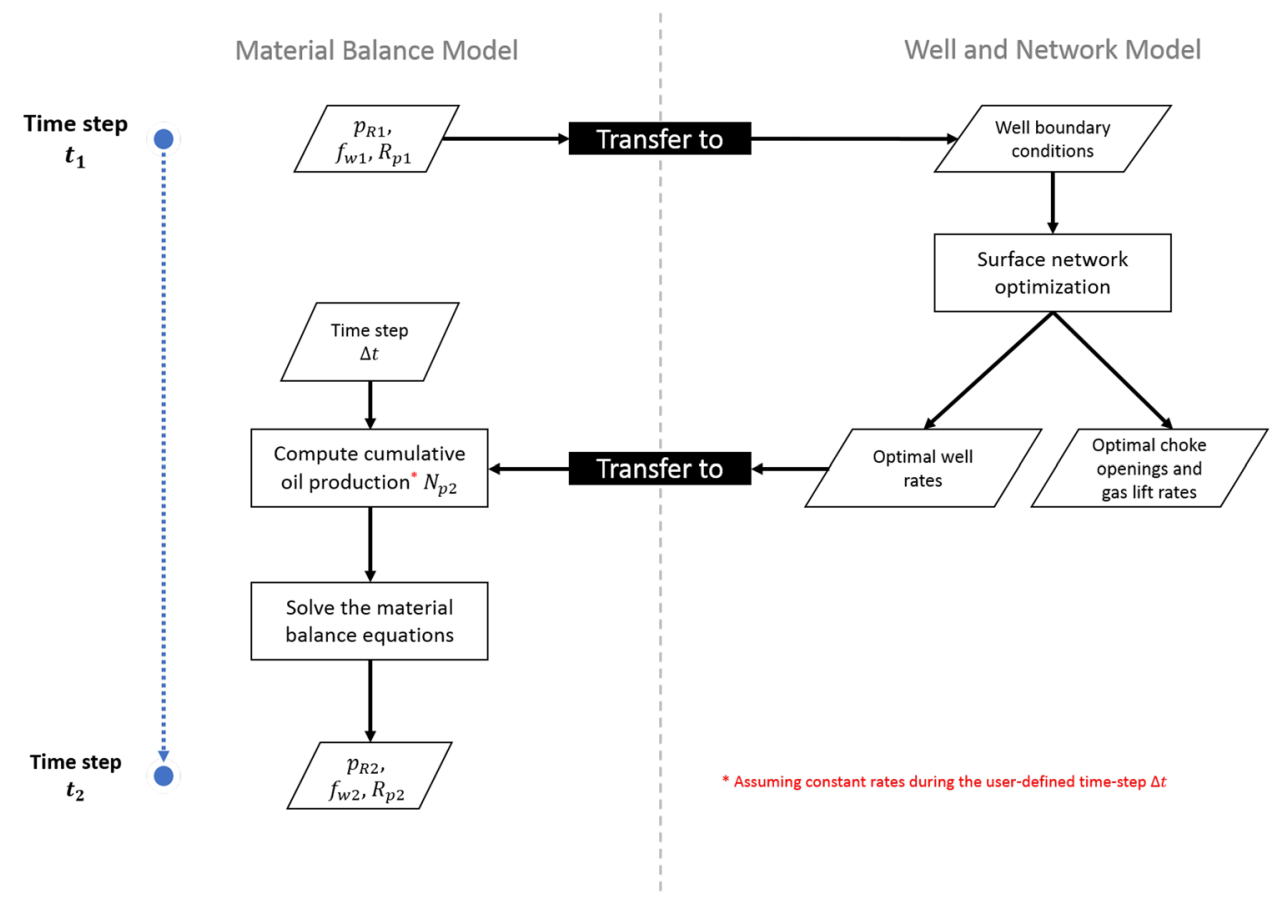

Table 1 Reservoir properties

\begin{tabular}{lcc}
\hline & Reservoir A & Reservoir B \\
\hline Initial pressure (psia) & 4650 & 3905 \\
Oil API gravity $\left({ }^{\circ} \mathrm{API}\right)$ & 37 & 39 \\
Initial GOR (scf/stb) & 800 & 500 \\
Reservoir temperature $\left({ }^{\circ} \mathrm{F}\right)$ & 210 & 250 \\
Bubble point (psia) & 3150 & 2300 \\
\hline
\end{tabular}

Well performance is modeled with vertical lift performance tables that depict required bottom-hole pressure as a function of oil rate, wellhead pressure, gas lift rate, and WC. Wells are naturally flowing in the early stage of the field and are boosted with gas lift injection in the later phase. Vertical lift performance (VLP) models are built in a commercial black-oil steady-state simulator.

Well characteristics, layout, and configuration are provided in Appendix A.

\section{Network model}

In the surface network, the pipeline between manifolds A and $\mathrm{B}$ is $7.5 \mathrm{~km}$ long and has an inner diameter of $8^{\prime \prime}$. The pipeline between manifold $\mathrm{B}$ and the production separator is $12 \mathrm{~km}$ long and has an inner diameter of $12^{\prime \prime}$. The flowlines that connect the wellhead to manifolds A and B are short and have an inner diameter of $8^{\prime \prime}$.

The network model is built in a commercial steady-state simulator.

\section{Surface process}

The production separator is operated at a constant pressure of 200 psia.

\section{Network optimization}

\section{Non-linear formulation}

For some given reservoir conditions (reservoir pressure, GOR, WC) at a given time, the objective function is to maximize the field oil production:

$\max q_{o}^{\text {tot }}$,

by changing choke openings and the gas lift allocated to each well $j$. The optimization problem is subject to the following field constraints:

$q_{\text {liq }}^{\text {tot }} \leq q_{\text {liq }}^{\max }$,

due to constraints in the production separator, and

$q_{\mathrm{gl}}^{\text {tot }} \leq q_{\mathrm{gl}}^{\max }$,

due to gas lift injection capacity. Note that in the early phase of the field, gas lift is not available, and therefore, $q_{\mathrm{gl}}^{\max }$ is set to 0 .

In addition, each well $j$ is subject to an operational constraint to avoid sand production:

$q_{\mathrm{o}}^{j} \leq q_{\mathrm{o}}^{\max }$, 
with $q_{\mathrm{o}}^{\max }=10000 \mathrm{stb} /$ day.

\section{Linear formulation}

The optimization problem has been reformulated as a mixed integer linear problem, to speed up the optimization runtime. To do so, all dependencies have to be explicitly expressed. This is a major difference compared to traditional non-linear black-box optimization, where part of the calculation (e.g., the well performance) are totally invisible to the solver. In particular, the network has to be modeled and solved within the optimization formulation. This is achievable by fist splitting the network model into smaller independent elements. An independent element is defined by an inlet and an outlet with a constant GOR, WC, and mass rate.

Well modeling

Wells are modeled with a collection of points that depicts oil production as a function of wellhead pressure and gas lift injected. For well $j$ :

$q_{\mathrm{o}}^{j}=q_{\mathrm{o}}^{j}\left(p_{\mathrm{wh}}^{j}, q_{\mathrm{gl}}^{j}\right)$.

These functions are created by executing the commercial black-box simulator with several combinations of input $\left(p_{\mathrm{wh}}, q_{\mathrm{gl}}\right)$. The WC and GOR of the well are assumed to be constant during the simulation. WC, GOR, and reservoir pressure are then varied in the simulator and new well tables are generated to take into account the effect of reservoir depletion. Figure 3 shows an example of such a function for a well of reservoir A.

\section{Flowline modeling}

Flowlines are modeled as a collection of points that depicts pressure drops $(\Delta p)$ as a function of liquid rate $\left(q_{\mathrm{liq}}\right)$, producing WC $\left(f_{\mathrm{w}}\right)$, total GOR $\left(R_{\mathrm{p}}\right)$ and inlet pressure $p_{\text {in }}$ :

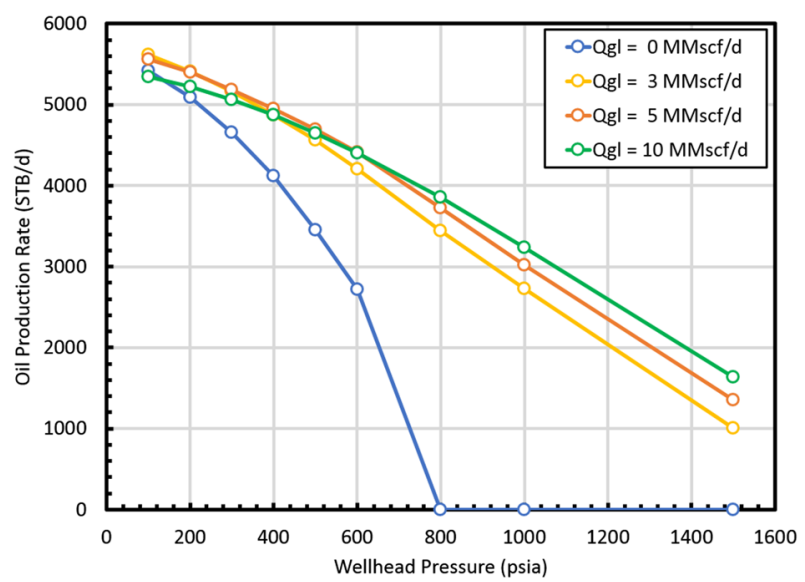

Fig. 3 Example of a well performance model for a well of reservoir A with a reservoir pressure of 3500 psia, producing GOR of $800 \mathrm{scf} / \mathrm{stb}$ and $\mathrm{WC}$ of $30 \%$
$\Delta p=\Delta p\left(q_{\mathrm{liq}}, f_{\mathrm{w}}, R_{\mathrm{p}}, p_{\mathrm{in}}\right)$.

The total GOR $R_{\mathrm{p}}$ is given by

$R_{\mathrm{p}}=\frac{q_{\mathrm{g}}^{\mathrm{res}}+q_{\mathrm{gl}}}{q_{\mathrm{o}}}$.

Figures 4, 5 and 6 show an example of such a function for pipeline A.

\section{Network equilibrium modeling}

The network hydraulic flow equilibrium is modeled as part of the optimization formulation using equality constraints at each junction between two independent elements. On the example of Fig. 7, the flow equilibrium in the node is modeled as follows:

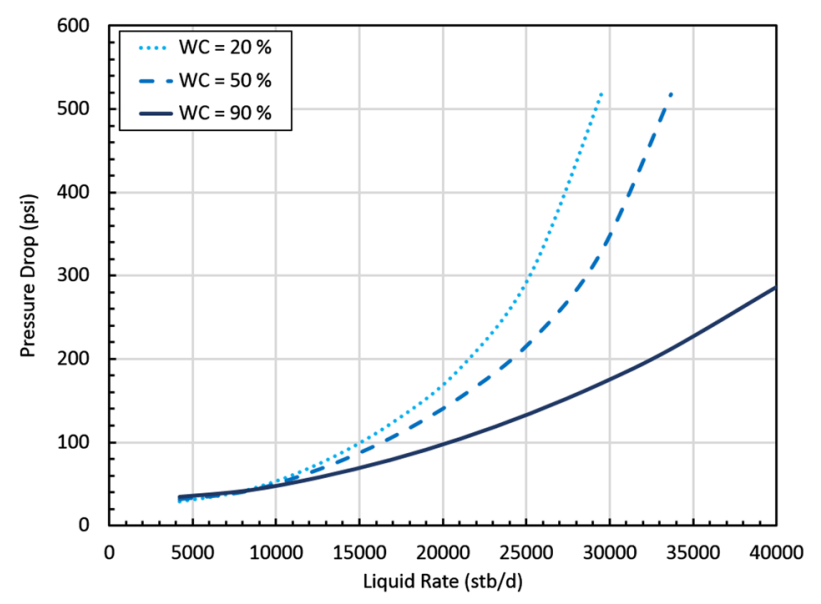

Fig. 4 Influence of the producing WC on the performance curve of pipeline A. The GOR is held constant and equal to $700 \mathrm{scf} / \mathrm{stb}$ and the inlet pressure is equal to $700 \mathrm{psia}$

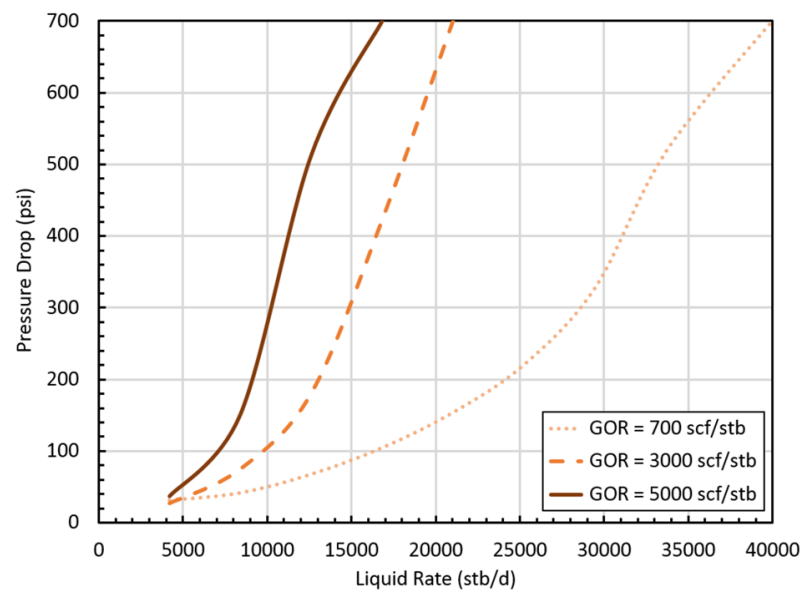

Fig. 5 Influence of the producing GOR on the performance curve of pipeline A. The WC is held constant and equal to $45 \%$ and the inlet pressure is equal to $700 \mathrm{psia}$ 


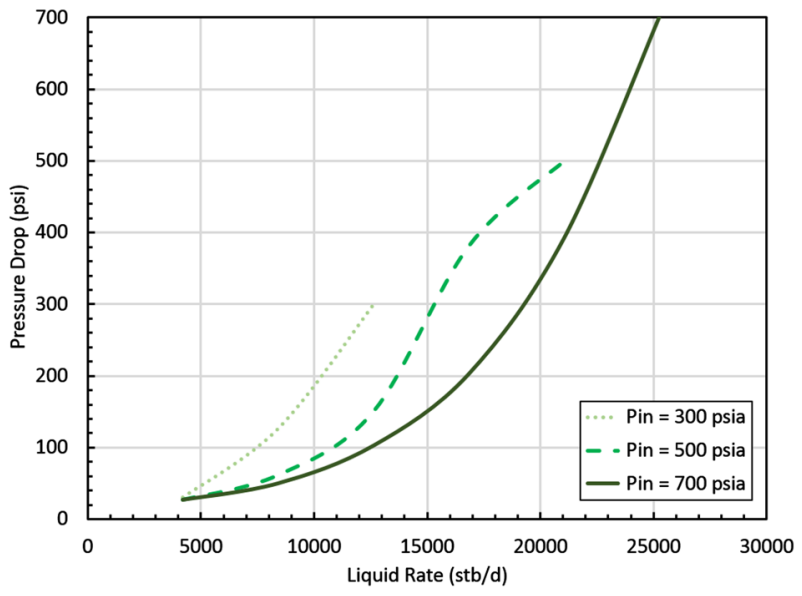

Fig. 6 Influence of the inlet pressure on the performance curve of pipeline A. The WC and GOR are held constant and equal to $45 \%$ and $1800 \mathrm{scf} / \mathrm{stb}$ respectively

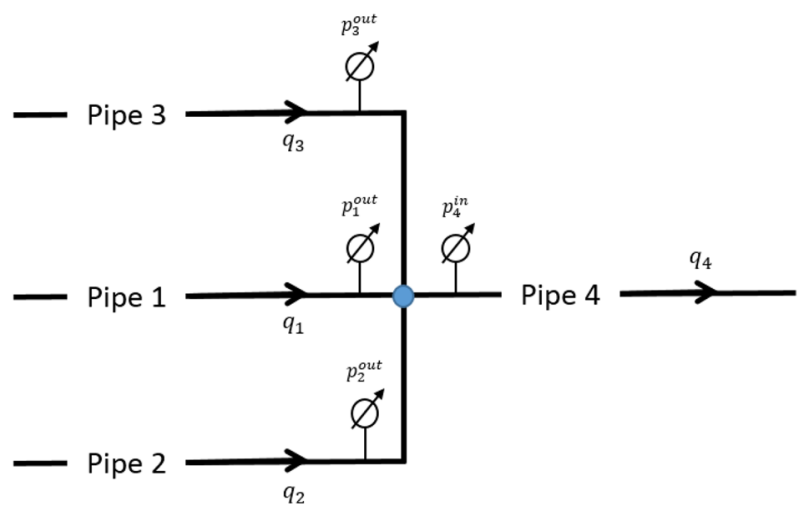

Fig. 7 Modeling of flow equilibria in a production network (after Hoffmann and Stanko 2017)

$p_{1}^{\text {out }}=p_{2}^{\text {out }}=p_{3}^{\text {out }}=p_{4}^{\text {in }}$,

$q_{4}=q_{1}+q_{2}+q_{3}$.

Additional fluid properties can be calculated. For instance, the WC in pipe 4 can be obtained from the WC of the other pipes:

$f_{\mathrm{w}}^{(4)}=\frac{q_{1} \cdot f_{\mathrm{w}}^{(1)}+q_{2} \cdot f_{\mathrm{w}}^{(2)}+q_{3} \cdot f_{\mathrm{w}}^{(3)}}{q_{1}+q_{2}+q_{3}}$.

\section{SOS2 piecewise linear approximation}

The well and pipeline flow functions described above are strongly non-linear. They are approximated using linear segments (as shown in Fig. 8). Interpolating between

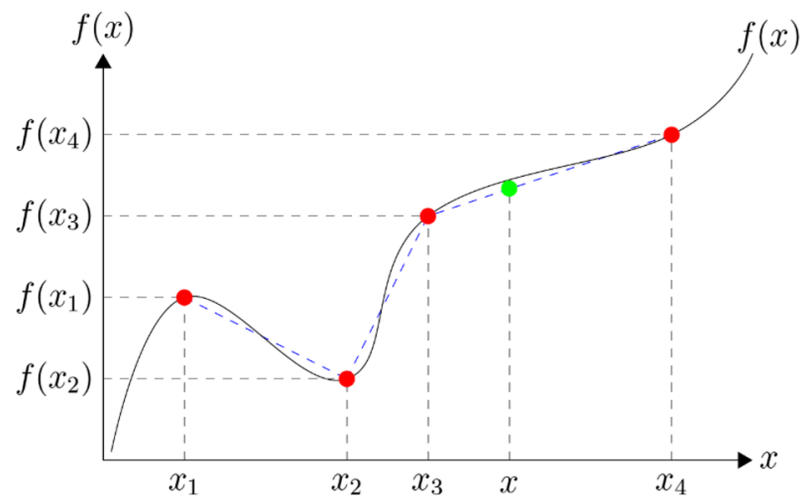

Fig. 8 SOS2 models in one dimension

the breakpoints is achieved using SOS2 models, see Fig. 8. An SOS2 is an ordered set of non-negative variables, of which at most two can be non-zero, and if two are non-zero these must be consecutive in their ordering. For example, the SOS2 piecewise linear approximation of a one-dimensional function $f$ can be written as follows:

$\widetilde{f}(x)=\sum_{i=1}^{N} \lambda_{i} \cdot f\left(x_{i}\right)$

where $\left(\lambda_{i}\right)_{1 \leq i \leq N}$ is a set of positive weighting factors. Additionally, the independent variable $x$ is also expressed as a function of $\lambda_{i}$ :

$x=\sum_{i=1}^{N} \lambda_{i} \cdot x_{i}$

The SOS2 model imposes the set of weighting coefficients $\left(\lambda_{i}\right)_{1 \leq i \leq N}$ to be a SOS2. In addition

$\sum_{i=1}^{N} \lambda_{i}=1$.

In the case shown in Fig. $8, \lambda_{1}=\lambda_{2}=0, \lambda_{3} \neq 0, \lambda_{4} \neq 0$ and $\lambda_{3}+\lambda_{4}=1$.

Note that in an MILP optimization formulation, the weighting factors $\left(\lambda_{i}\right)_{1 \leq i \leq N}$ are variables and Eqs. (11), (12) and (13) are constraints.

The difference between $f(x)$ and its piecewise approximation $\widetilde{f}(x)$ can be minimized by increasing the number of breakpoints $x_{i}$. More breakpoints mean more weighting factors $\lambda_{i}$; therefore, more variables in the optimization problem and ultimately longer optimization runtime. Consequently, there is a balance to find between accuracy and runtime. 
Table 2 Parameters used in the reference case

\begin{tabular}{ll}
\hline Parameter & Value \\
\hline Field liquid capacity & 20,000 stb/day \\
Gas lift start-up & After 4 years \\
Gas lift injection capacity & 10 MMscf/day \\
Duration of the operations & 20 years max. \\
Time step size & 2 months \\
\hline
\end{tabular}

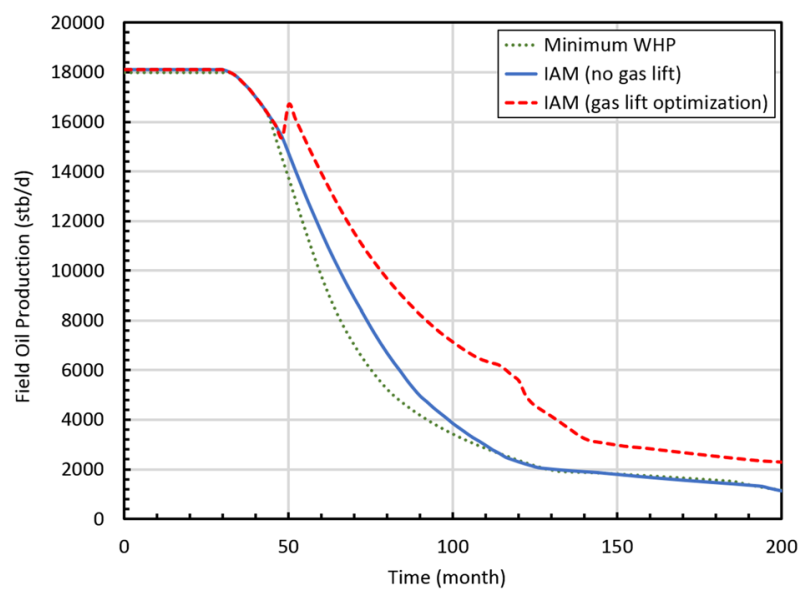

Fig. 9 Comparison of three production forecasts: (1) isolated approach with minimum WHP as boundary condition; (2) integrated approach without gas lift; and (3) integrated approach with gas lift optimization

\section{Resulting mixed integer linear program}

The non-linear optimization problem can be reformulated into a Mixed Integer Linear Program (MILP) by piecewise linearising all performance functions using SOS2 models. The integer variables (in fact, binary variables) are consequences of the usage of SOS2 models. Appendices B and $\mathrm{C}$ give the complete details of MILP formulation of the problem.

In this paper, we use the simplex with the branch and cut algorithm implemented in a commercial solver. Default solver settings are used.

\section{Results}

\section{Production forecast}

In this section, we show the benefits of using a coupled method compared to traditional "silo approach. We defined a reference case, see Table 2.

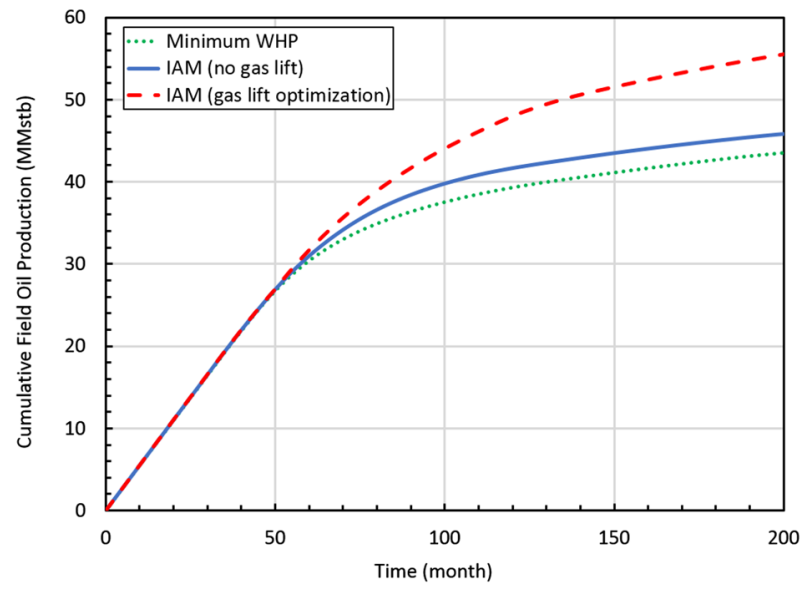

Fig. 10 Comparison of cumulative production for three production forecasts: (1) isolated approach with minimum WHP as boundary condition, (2) integrated approach without gas lift and (3) integrated approach with gas lift optimization

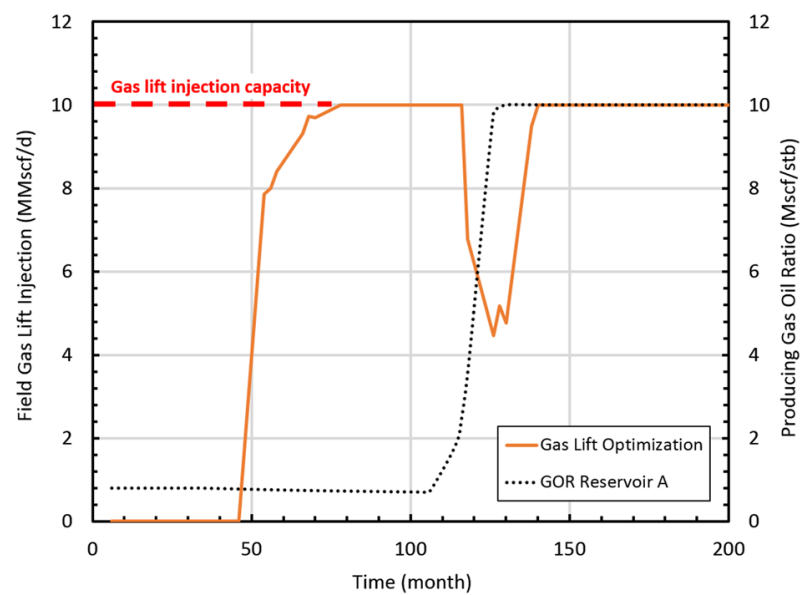

Fig. 11 Optimal field gas lift rate as a function of time

Figures 9 and 10 compare the field production rate and cumulative production profile using three different methods:

1. Silo approach: material balance simulators with capacity constraints and minimum WHP as boundary conditions (400 psia for wells of reservoir A and 300 psia for wells of reservoir $\mathrm{B})$;

2. IAM without gas lift;

3. IAM with gas lift optimization at each time step.

Results show that using a coupled approach significantly impacts the production forecast and, therefore, the project value. There is a difference of $12 \mathrm{MMstb}$ in cumulative oil produced between the silo approach (minimum WHP) and the IAM with gas lift optimization. 
Figure 11 shows that the optimization solution only injects the optimal quantity of gas lift which can be below the gas lift capacity.

The integrated solution approximately takes $20 \mathrm{~min}$ to generate one production forecast on an Intel@ Core $^{\mathrm{TM}} \mathrm{i} 7-5600 \mathrm{U}$ CPU $(2.60 \mathrm{GHz})$. In average, it takes around $7.5 \mathrm{~s}$ per time step. The execution bottleneck in the proposed solution is the network optimizer, see Fig. 12. Note that the runtime of the network optimization using the proposed MILP formulation is approximately 2-3 times faster than traditional non-linear surface network optimizer, which leads to considerably reduced runtime for the coupled solution. A lower execution runtime allows the user to run more scenarios, assessing more development alternatives and uncertainty.

\section{Economical analysis and field development}

\section{Economical data}

The NPV of a typical oil and gas project is normally defined by

$\mathrm{NPV}=\sum_{y=0}^{N_{\text {years }}} \frac{R_{y}}{(1+i)^{y}}-E_{\mathrm{cap}}$,

where $R_{y}$ is the net revenue of year $y$ (lumped revenue from oil minus operational expenses), $E_{\text {cap }}$ is the capital expenditure (assumed to be concentrated at time 0 ) and $N_{\text {years }}$ the life time (in years) of the field.

In this paper, the CAPEX is split into two: (1) initial CAPEX including installation of the platform, flowlines, and surface equipment and drilling of wells and (2) additional CAPEX related to installation of gas lift equipment (well completion, gas lift distribution system, and topside gas lift injection facilities). Thus, Eq. (14) becomes

$\mathrm{NPV}=\sum_{y=0}^{N_{\text {years }}} \frac{R_{y}}{(1+i)^{y}}-E_{\text {cap }}^{\mathrm{init}}-\frac{E_{\mathrm{cap}}^{\mathrm{gl}}}{(1+i)^{y_{\mathrm{gl}}}}$,

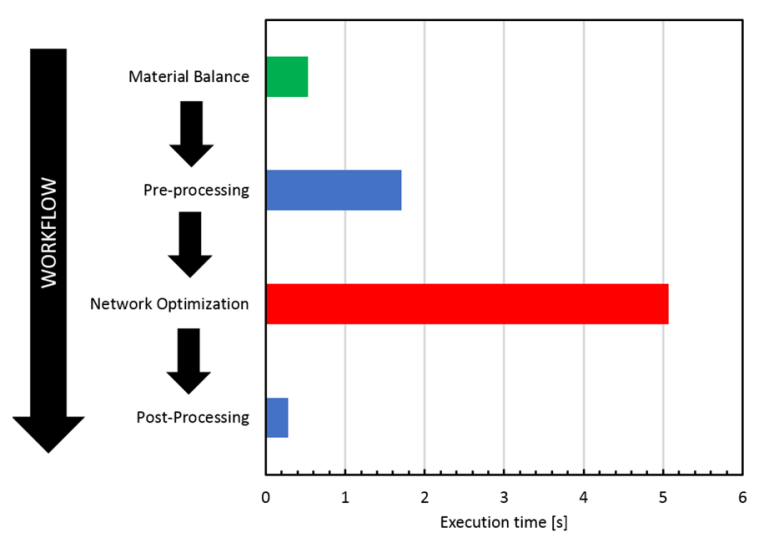

Fig. 12 Execution time of the solution for a single time step where $E_{\text {cap }}^{\text {init }}$ is the initial CAPEX, $E_{\text {cap }}^{\mathrm{gl}}$ is the CAPEX related to gas lift and $y_{\mathrm{gl}}$ is the year when the gas lift system is deployed.

After each run of the coupled solution, the NPV can be calculated:

1. The revenue of a given year $y$ is given by

$$
R_{y}=P_{\mathrm{o}} \cdot V_{\mathrm{oy}}-E_{\mathrm{op}} \text {, }
$$

where $P_{\mathrm{o}}$ is the current oil price, $V_{\mathrm{o} y}$ is the volume of oil produced during year $y$, and $E_{\mathrm{op}}$ is the operational expenditure. We assume here that gas does not generate any revenue (flared, re-injected or used as gas lift).

2. The CAPEX $E_{\text {cap }}^{\text {init }}$ depends on the initial surface installations (e.g., treatment capacity).

3. The CAPEX $E_{\text {cap }}^{\mathrm{gl}}$ depends on the surface installation size related to gas lift.

In this paper, we assume the oil price $P_{\mathrm{o}}$ to be constant over the lifetime of the field. $E_{\text {op }}$ and $E_{\text {cap }}$ are assumed to be solely a function of the liquid capacity and gas lift capacity. Numerical data used in the study are presented in Table 3. Figures 13, 14 and 15 give the profile of CAPEX and OPEX as a function of liquid capacity and gas lift injection capacity. In this paper, we assume that CAPEX is distributed during 3 years before start-up of production $(25 \%, 25 \%$ and $50 \%)$.

Table 3 Numerical values of key field development parameters

\begin{tabular}{ll}
\hline Parameter & Value \\
\hline Oil price $P_{\mathrm{o}}$ & $70 \mathrm{USD} / \mathrm{stb}$ \\
Interest rate $i$ & $8 \%$ \\
\hline
\end{tabular}

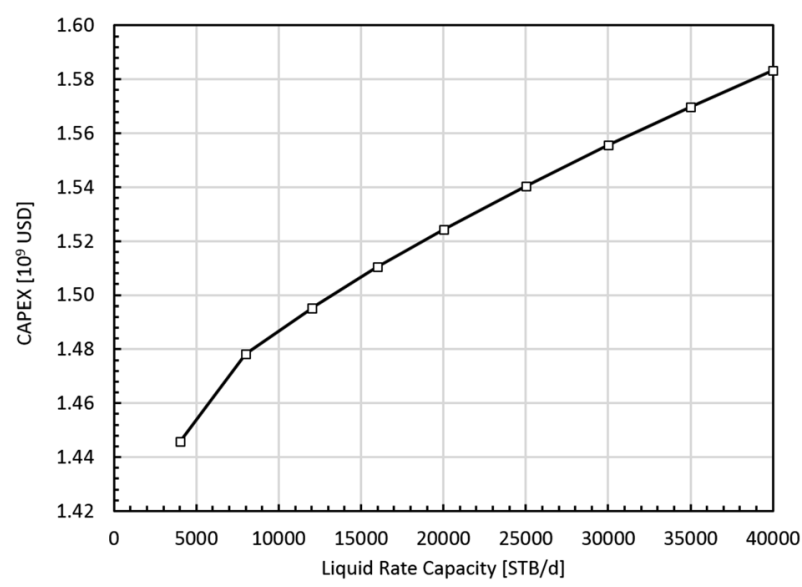

Fig. 13 Initial CAPEX as a function of liquid capacity. The gas lift system is not included in this CAPEX 


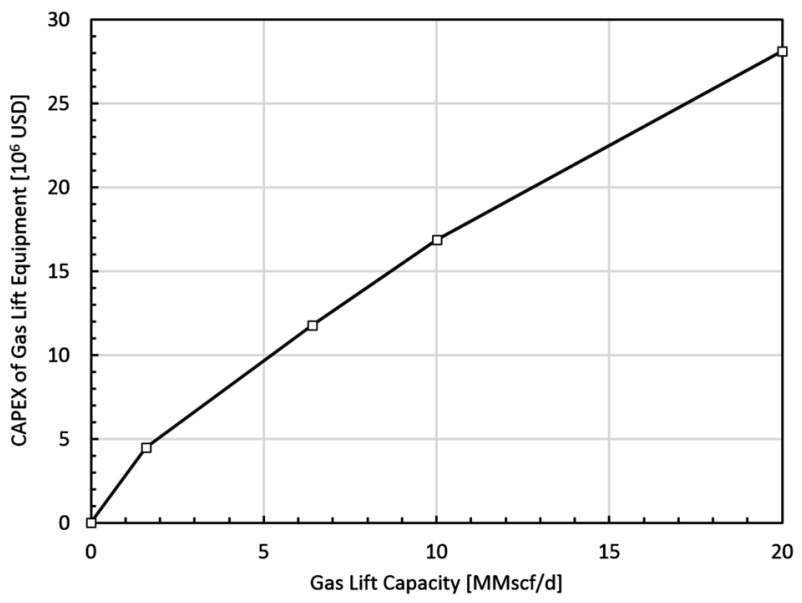

Fig. 14 CAPEX related to the gas lift system installation as a function of gas lift injection capacity

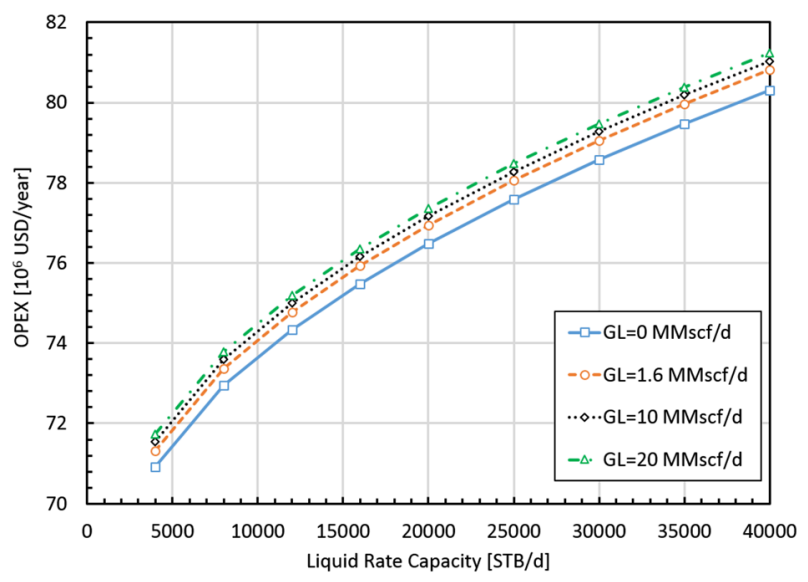

Fig. 15 Yearly OPEX as function of liquid capacity and gas lift injection capacity

Table 4 Main economical results for the reference case

\begin{tabular}{ll}
\hline KPI & Value \\
\hline Project NPV & 893.5 million \\
& USD (of year 0) \\
Initial CAPEX & 1.52 billion USD \\
Secondary CAPEX & 12.1 million USD \\
Duration of operations & 17 years \\
\hline
\end{tabular}

\section{Application to the reference case}

Table 4 gives the main results when applying the economical data to the reference production profile. Figure 16 shows the cash flow analysis.

Figure 17 shows that the revenues stream have the greatest impact on the project NPV. Revenue streams depend on

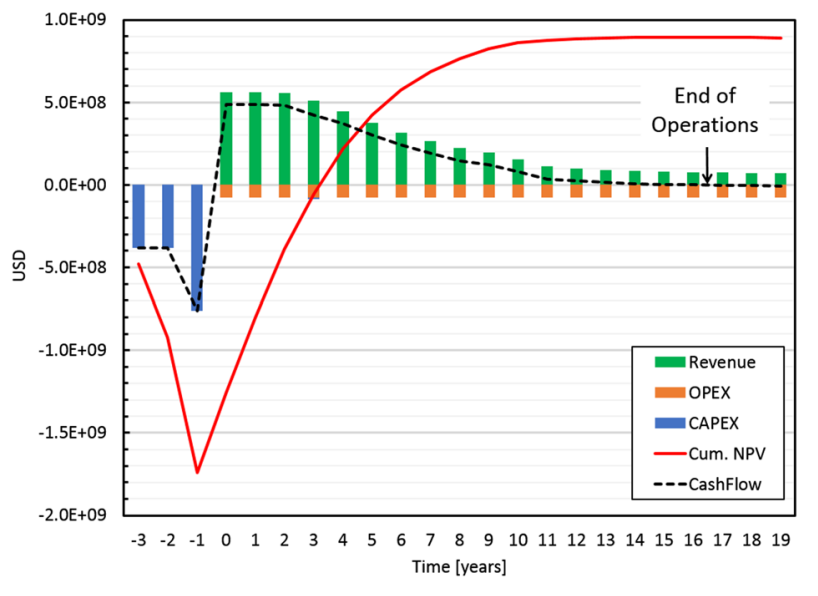

Fig. 16 Cash flow analysis for the reference case of Table 2

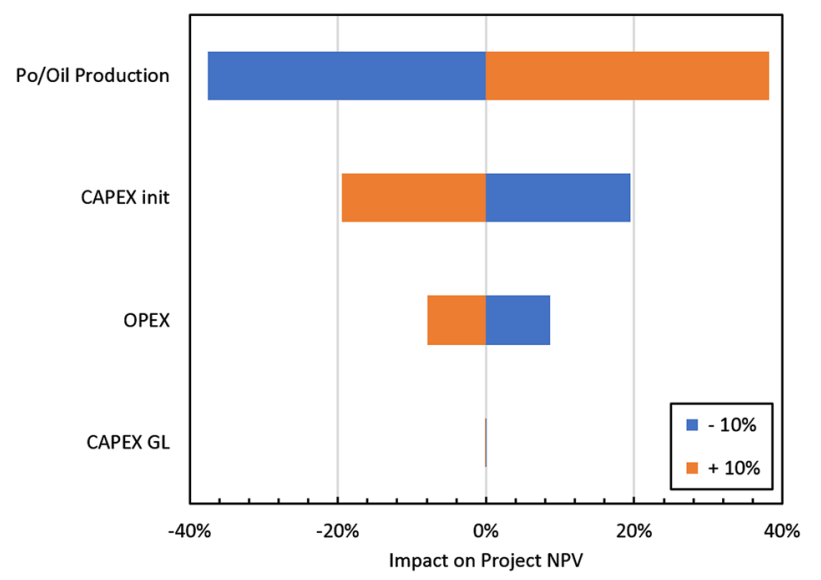

Fig. 17 Impact of each parameter on the project NPV

(1) a good estimation of the future oil price and (2) an accurate production forecast.

\section{Field development optimization}

We used the proposed solution to optimize three field design parameters: (1) the liquid capacity; (2) the gas lift capacity; and (3) the gas lift start-up. Figures 18 and 19 and Table 5 give the impact of liquid and gas lift capacity on the project NPV (the gas lift start-up date is held constant and equal to 48 months). The base case NPV can be increased by up to 75 millions USD compared to the base case by choosing a proper combination of liquid capacity and gas lift capacity.

We also studied the effect of the gas lift start-up date on the project NPV, see Fig. 20. Results show that for the case studied, it is most convenient to start gas lift as early as possible. In this paper, we did not account for constraints related to logistics (hardware delivery, installation, rig availability, 
Fig. 18 NPV as a function of liquid and gas lift capacities. The red square indicates the sweet zone to be further investigated for optimization
NPV $[1 E+8$ USD $]$

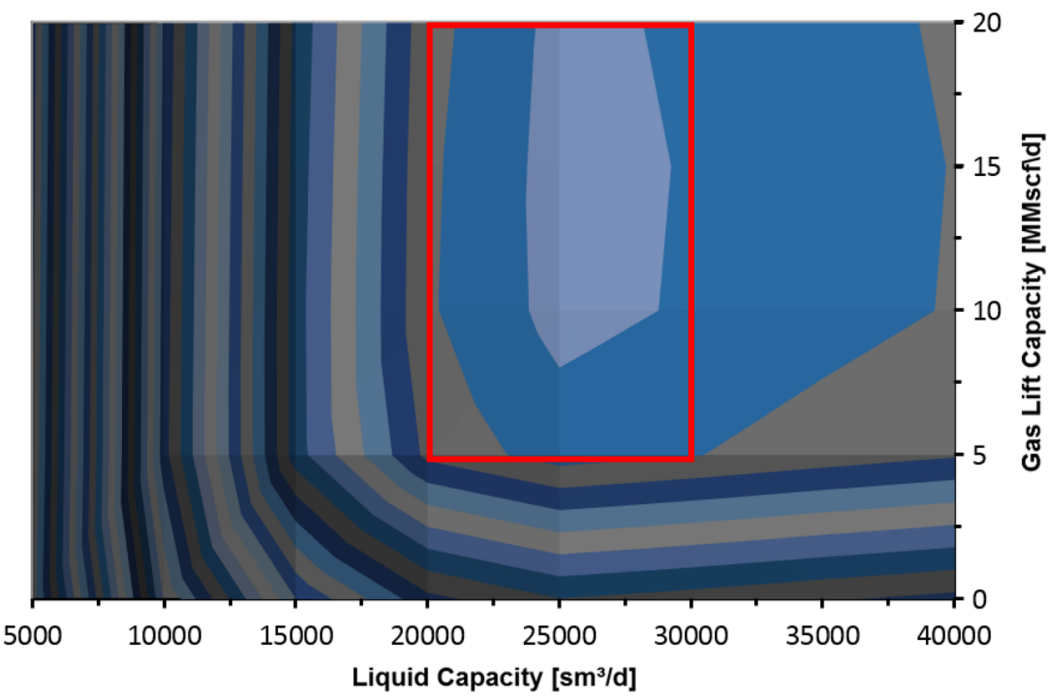

\begin{tabular}{|c|c|c|c|c|c|c|c|c|c|}
\hline -10.0--9.5 & $=-9.5--9.0$ & ㅁ. -9.0--8.5 & $\overline{0}-8.5--8.0$ & $-8.0--7.5$ & $=-7.5--7.0$ & $=-7.0--6.5$ & $-6.5--6.0$ & $\square-6.0--5.5$ & $m-5.5-5.0$ \\
\hline$=-5.0--4.5$ & $=-4.5--4.0$ & $=-4.0--3.5$ & $=-3.5--3.0$ & $=-3.0--2.5$ & $=-2.5--2.0$ & $=-2.0-1.5$ & $=-1.5-1.0$ & $\square-1.0-0.5$ & $=-0.5-0.0$ \\
\hline$=0.0-0.5$ & $=0.5-1.0$ & $=1.0-1.5$ & $=1.5-2.0$ & $=2.0-2.5$ & $=2.5-3.0$ & $=3.0-3.5$ & $=3.5-4.0$ & $=4.0-4.5$ & $=4.5-5.0$ \\
\hline$=5.0-5.5$ & $=5.5-6.0$ & 6.0-6.5 & $6.5-7.0$ & $7.0-7.5$ & $=7.5-8.0$ & $=8.0-8.5$ & $=8.5-9.0$ & - $9.0-9.5$ & $9.5-10.0$ \\
\hline
\end{tabular}

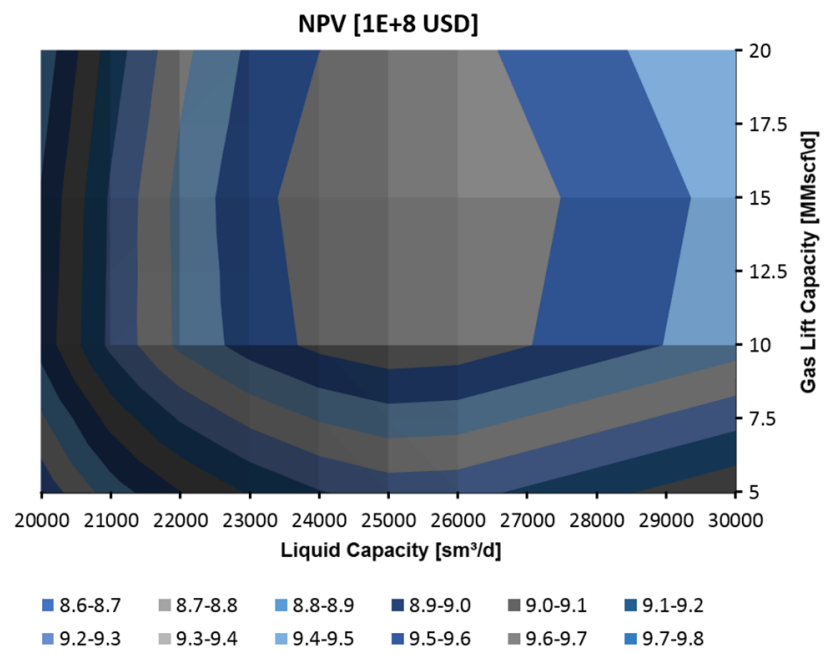

Fig. $19 \mathrm{NPV}$ as a function of liquid and gas lift capacities limited to the sweet zone of Fig. 18

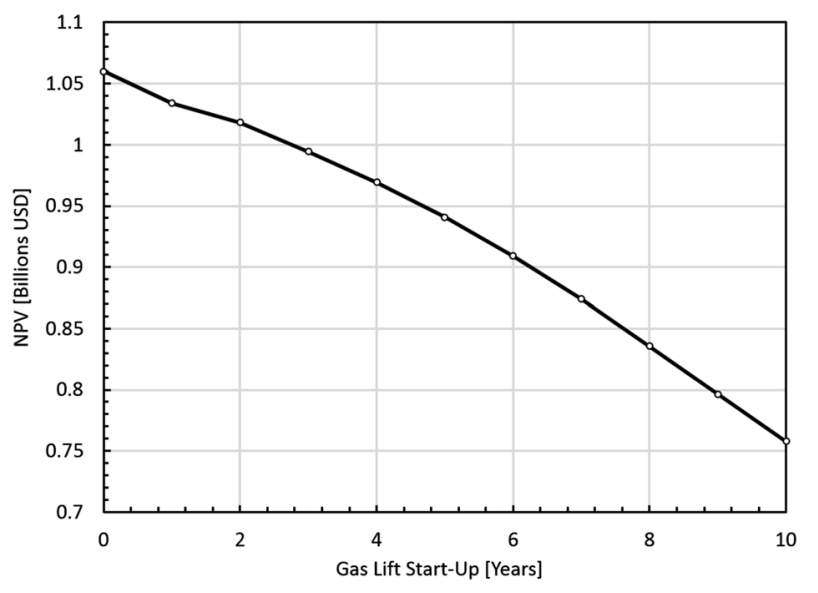

Fig. 20 NPV as a function of gas lift start-up date
Table 5 NPV (in 1E8 USD) as a function of liquid rate and gas lift capacities

\begin{tabular}{|c|c|c|c|c|c|c|c|c|c|}
\hline & & \multicolumn{8}{|c|}{ Liquid capacity $\left(\mathrm{sm}^{3} /\right.$ day $)$} \\
\hline & & 5000 & 10,000 & 15,000 & 20,000 & 25,000 & 30,000 & 35,000 & 40,000 \\
\hline \multirow{5}{*}{$\begin{array}{c}\text { Gas lift capacity } \\
\text { (MMscf/day) }\end{array}$} & 0 & -9.32 & -0.46 & 3.48 & 5.35 & 5.98 & 5.78 & 5.55 & 5.34 \\
\hline & 5 & -9.51 & 0.80 & 6.28 & 8.63 & 9.24 & 9.02 & 8.78 & 8.55 \\
\hline & 10 & -9.62 & 0.73 & 6.30 & 8.94 & 9.67 & 9.44 & 9.20 & 8.96 \\
\hline & 15 & -9.71 & 0.67 & 6.24 & 8.91 & 9.69 & 9.47 & 9.22 & 8.98 \\
\hline & 20 & -9.79 & 0.58 & 6.15 & 8.83 & 9.64 & 9.42 & 9.17 & 8.94 \\
\hline
\end{tabular}

The numbers in italic indicate the sweet zone to be further investigated 
etc.) which can have a great impact on the field development planning.

\section{Conclusions}

- A methodology to perform field production forecasting and scheduling is presented and discussed. The methodology successfully maximizes oil production in each depletion step by varying gas lift rate and honoring multiple operational constraints.

- The running times of the proposed methodology are low and might be suitable for early field development studies that require to perform multiple sensitivity studies and uncertainty analysis.

- The methodology was then used to optimize field design. Optimum ranges for liquid processing capacity and gas lift capacity were determined by brute force exploration of NPV function. The difference between the minimum and maximum NPV in the explored space is substantial.

- Optimal gas lift start-up was also determined in the same manner. It seems it is best to start gas lift from field production start-up.

\section{Further work}

The methodology presented in this paper should be applied to other use cases with more wells. Good candidates are systems with routing issues (e.g., HP/LP lines or routing between platforms). This work has employed a material balance model to represent the reservoir. It should be extended for cases with a 3D reservoir simulation.

\section{Unit conversion}

\begin{tabular}{lll}
\hline Field & Conversion & S.I. \\
\hline $1 \mathrm{psi}$ & $=6.894757$ & $\mathrm{~Pa}$ \\
$1 \mathrm{ft}$ & $=0.3048$ & $\mathrm{~m}$ \\
$1 \mathrm{in}$ & $=0.0254$ & $\mathrm{~m}$ \\
$1 \mathrm{bbl}$ & $=0.1589873$ & $\mathrm{~m}^{3}$ \\
$1 \mathrm{cf}$ & $=0.028316846592$ & $\mathrm{~m}^{3}$ \\
$1 \mathrm{BTU}$ & $=1055.06$ & $\mathrm{~J}$ \\
$1 \mathrm{lb}$ & $=0.453592$ & $\mathrm{~kg}$ \\
${ }^{\circ} \mathrm{API}$ & $\rho=141.5 /\left(131.5+\gamma_{\mathrm{API}}\right)$ & $\mathrm{g} / \mathrm{cm}^{3}$ \\
${ }^{\circ} \mathrm{F}$ & ${ }^{\circ} \mathrm{C}=\left({ }^{\circ} \mathrm{F}-32\right) / 1.8$ & ${ }^{\circ} \mathrm{C}$ \\
\hline
\end{tabular}

Open Access This article is distributed under the terms of the Creative Commons Attribution 4.0 International License (http://creat ivecommons.org/licenses/by/4.0/), which permits unrestricted use, distribution, and reproduction in any medium, provided you give appropriate credit to the original author(s) and the source, provide a link to the Creative Commons license, and indicate if changes were made.

\section{Additional data}

Tables $6,7,8$, and 9 give more details about the production system.

\section{Mixed integer linear formulation of the optimization problem}

This part presents the MILP formulation used to solve the optimization problem presented above (Table 10):

Table 6 Reservoir A data

\begin{tabular}{ll}
\hline Parameter & Value \\
\hline Solution GOR (scf/stb) & 800 \\
Oil gravity $\left({ }^{\circ} \mathrm{API}\right)$ & 37 \\
Gas gravity & 0.76 \\
Water salinity & 23000 \\
$\mathrm{~Pb}, \mathrm{Rs}$, Bo correlations & Glas $\varnothing$ \\
Oil viscosity correlation & Beal et al. \\
$C_{\mathrm{p}}$ oil $(\mathrm{BTU} / \mathrm{lb} / \mathrm{F})$ & 0.53 \\
$C_{\mathrm{p}}$ gas $(\mathrm{BTU} / \mathrm{lb} / \mathrm{F})$ & 0.51 \\
$C_{\mathrm{p}}$ water $(\mathrm{BTU} / \mathrm{lb} / \mathrm{F})$ & 1 \\
\hline
\end{tabular}

Table 7 Reservoir B data

\begin{tabular}{ll}
\hline Parameter & Value \\
\hline Solution GOR (scf/stb) & 500 \\
Oil gravity ( $\left.{ }^{\circ} \mathrm{API}\right)$ & 39 \\
Gas gravity & 0.798 \\
Water salinity & 100,000 \\
Pb, Rs, Bo correlation & Glas $\varnothing$ \\
Oil viscosity correlation & Beggs et al. \\
$C_{\mathrm{p}}$ oil $(\mathrm{BTU} / \mathrm{lb} / \mathrm{F})$ & 0.53 \\
$C_{\mathrm{p}}$ gas $(\mathrm{BTU} / \mathrm{lb} / \mathrm{F})$ & 0.51 \\
$C_{\mathrm{p}}$ water $(\mathrm{BTU} / \mathrm{lb} / \mathrm{F})$ & 1 \\
\hline
\end{tabular}

Table 8 Heat transfer parameters

\begin{tabular}{lc}
\hline Parameter & Value \\
\hline Seabed temperature $\left({ }^{\circ} \mathrm{F}\right)$ & 40 \\
Reservoir B temperature $\left({ }^{\circ} \mathrm{F}\right)$ & 250 \\
Reservoir A temperature $\left({ }^{\circ} \mathrm{F}\right)$ & 210 \\
Wellbore overall heat transfer coefficient $\left(\mathrm{BTU} / \mathrm{h} / \mathrm{ft}^{2} / \mathrm{F}\right)$ & 8
\end{tabular}


Table 9 Well completion details

\begin{tabular}{lcllll}
\hline Well & $\begin{array}{l}\text { Target formation } \\
\text { MD (ft) }\end{array}$ & $\begin{array}{l}\text { Target formation } \\
\text { TVD (ft) }\end{array}$ & Tubing ID (in) & $\begin{array}{l}\text { Gas lift valve } \\
\text { depth (ft) }\end{array}$ & $\begin{array}{l}J \text { (Linear + } \\
\text { Vogel) (stb/day/ } \\
\text { psi) }\end{array}$ \\
\hline Well 1A & 9275 & 9000 & 4.052 & 7027.6 & 7.1500 \\
Well 2A & 9000 & 9000 & 4.052 & 7641.4 & 7.1486 \\
Well 3A & 12,000 & 8000 & 4.052 & 8010.7 & 7.1486 \\
Well 1B & 8000 & 8000 & 4.052 & 6794.3 & 0.7212 \\
Well 2B & 8000 & 8000 & 4.052 & 6947.8 & 0.7218 \\
Well 3B & 8000 & 8000 & 4.052 & 6968.7 & 0.7218 \\
\hline
\end{tabular}

Table 10 Sets of wells and flowlines

\begin{tabular}{ll}
\hline Set & Description \\
\hline $\mathcal{W}$ & Set of all wells \\
$\mathcal{L}$ & Set of all flowlines \\
$\mathcal{W}_{f}$ & Set of wells \\
& producing into \\
& flowline $f$ \\
\hline
\end{tabular}

Table 11 Field variables

\begin{tabular}{ll}
\hline Variable & Description \\
\hline$q_{\mathrm{o}}^{\text {tot }}$ & Total oil production rate \\
$q_{\mathrm{w}}^{\text {tot }}$ & Total water production rate \\
$q_{\mathrm{g}}^{\text {tot }}$ & Total gas production rate \\
$q_{\mathrm{gl}}^{\text {tot }}$ & Total gas lift used \\
$q_{\mathrm{liq}}^{\text {tot }}$ & Total liquid rate \\
\hline
\end{tabular}

$\max _{\gamma} q_{o}^{\text {tot }}$

with $\gamma$ being the vector of all variables defined in Tables 11 , $12,13,14,15$ and 16. The optimization problem is subject to numerous constraints presented below.

\section{Field constraints}

$$
\begin{aligned}
& q_{\mathrm{o}}^{\mathrm{tot}}=\sum_{j \in \mathcal{W}} q_{\mathrm{o}}^{j}, \\
& q_{\mathrm{w}}^{\mathrm{tot}}=\sum_{j \in \mathcal{W}} q_{\mathrm{w}}^{j},
\end{aligned}
$$

Table 12 Well variables

\begin{tabular}{ll}
\hline Variable & Description \\
\hline$q_{\mathrm{w}}^{j}$ & Water production rate of well $j$ \\
$q_{\mathrm{o}}^{j}$ & Oil production rate of well $j$ \\
$q_{\mathrm{liq}}^{j}$ & Liquid production rate of well $j$ \\
$p_{\mathrm{wh}}^{j}$ & Wellhead pressured of well $j$ \\
$q_{\mathrm{gl}}^{j}$ & Gas lift rate used for well $j$ \\
$y_{j}$ & Status of well $j$ (open $=1$, closed $=0$ ) \\
\hline
\end{tabular}

Table 13 Flowline variables

\begin{tabular}{ll}
\hline Variable & Description \\
\hline$q_{\mathrm{w}}^{f}$ & Water production rate of flowline $f$ \\
$q_{\text {liq }}^{f}$ & Liquid production rate of flowline $f$ \\
$q_{\mathrm{g}}^{f}$ & Total gas production rate of flowline $f$ \\
$p_{\text {in }}^{f}$ & Inlet pressure of flowline $f$ \\
$p_{\text {out }}^{f}$ & Outlet pressure of flowline $f$ \\
$\Delta p_{f}$ & Pressure drop in flowline $f$ \\
\hline
\end{tabular}

Table 14 Sets of breakpoints used in the MILP formulation

\begin{tabular}{ll}
\hline Set & Description \\
\hline $\mathcal{P}_{\text {wh }}^{j}$ & Set of wellhead pressure breakpoints for well $j$ \\
$\mathcal{Q}_{\mathrm{gl}}^{j}$ & Set of gas lift rate breakpoints for well $j$ \\
$\mathcal{Q}_{\text {liq }}^{f}$ & Set of liquid rate breakpoints for flowline $f$ \\
$\mathcal{P}_{\text {in }}^{f}$ & Set of inlet pressure breakpoints for flowline $f$ \\
$\mathcal{F}_{\text {wc }}^{f}$ & Set of WC breakpoints for flowline $f$ \\
$\mathcal{F}_{\text {gor }}^{f}$ & Set of GOR breakpoints for flowline $f$ \\
\hline
\end{tabular}

Table 15 Auxiliary variables used in the MILP formulation

\begin{tabular}{ll}
\hline Var. & Description \\
\hline$\theta_{p q}^{j}$ & Weighting variable for breakpoint $(p, q)$, well $j$ \\
$\alpha_{p}^{j}$ & SOS2 variable for breakpoint $p$, well $j$ \\
$\beta_{q}^{j}$ & SOS2 variable for breakpoint $q$, well $j$ \\
$\Omega_{q_{l}, w, g, p}^{f}$ & Weighting variable for breakpoint $\left(q_{l}, w, g, p\right)$, flowline $f$ \\
$\lambda_{q_{l}}^{f}$ & SOS2 variable for breakpoint $q_{l}$, flowline $f$ \\
$\mu_{p}^{f}$ & SOS2 variable for breakpoint $p$, flowline $f$ \\
$\phi_{w}^{f}$ & SOS2 variable for breakpoint $w$, flowline $f$ \\
$\psi_{g}^{f}$ & SOS2 variable for breakpoint $g$, flowline $f$ \\
\hline
\end{tabular}


Table 16 Piecewise linear functions used in the MILP

\begin{tabular}{ll}
\hline Function & Description \\
\hline$\widehat{q_{\mathrm{o}}^{j}}$ & PWL function giving the oil rate of well $j$ as a function of wellhead pressure and gas lift rate \\
$\widehat{\Delta p}_{f}$ & PWL function giving the pressure drop in flowline $f$ as a function of liquid rate, producing \\
& WC, total GOR and inlet pressure \\
\hline
\end{tabular}

$$
\begin{aligned}
& q_{\mathrm{gl}}^{\mathrm{tot}}=\sum_{j \in \mathcal{W}} q_{\mathrm{gl}}^{j}, \\
& q_{\mathrm{g}}^{\mathrm{tot}}=\sum_{j \in \mathcal{W}} q_{\mathrm{g}}^{j}+q_{\mathrm{gl}}^{\mathrm{tot}}, \\
& q_{\mathrm{w}}^{\mathrm{tot}}+q_{\mathrm{o}}^{\mathrm{tot}} \leq q_{\mathrm{liq}}^{\mathrm{max}}, \\
& q_{\mathrm{gl}}^{\mathrm{tot}} \leq q_{\mathrm{gl}}^{\mathrm{max}} .
\end{aligned}
$$

\section{Well constraints}

For each well $j \in \mathcal{W}$ :

$$
\begin{aligned}
& q_{\mathrm{o}}^{j}=\sum_{p \in \mathcal{P}_{\mathrm{wh}}^{j}} \sum_{q \in \mathcal{Q}_{\mathrm{gl}}^{j}} \theta_{p q}^{j} \cdot \hat{q}_{\mathrm{o}}^{j}(p, q), \\
& p_{\mathrm{wh}}^{j}=\sum_{p \in \mathcal{P}_{\mathrm{wh}}^{j}} \sum_{q \in \mathcal{Q}_{\mathrm{gl}}^{j}} \theta_{p q}^{j} \cdot p, \\
& q_{\mathrm{gl}}^{j}=\sum_{p \in \mathcal{P}_{\mathrm{wh}}^{j}} \sum_{q \in \mathcal{Q}_{\mathrm{gl}}^{j}} \theta_{p q}^{j} \cdot q, \\
& \sum_{p \in \mathcal{P}_{\mathrm{wh}}^{j}} \sum_{q \in \mathcal{Q}_{\mathrm{gl}}^{j}} \theta_{p q}^{j}=1,
\end{aligned}
$$

$\forall p \in \mathcal{P}_{\mathrm{wh}}^{j}, \quad \forall q \in \mathcal{Q}_{\mathrm{gl}}^{j}, \quad \theta_{p q}^{j} \geq 0$,

$$
\forall p \in \mathcal{P}_{\mathrm{wh}}^{j}, \quad \alpha_{p}^{j}=\sum_{q \in \mathcal{Q}_{\mathrm{gl}}^{j}} \theta_{p q}^{j},
$$

$$
\forall q \in \mathcal{Q}_{\mathrm{gl}}^{j}, \quad \beta_{q}^{j}=\sum_{p \in \mathcal{P}_{\mathrm{wh}}^{j}} \theta_{p q}^{j},
$$

$\left(\alpha_{p}^{j}\right)_{p \in \mathcal{P}_{\mathrm{wh}}^{j}}$ is a SOS2, $\left(\beta_{q}^{j}\right)_{q \in \mathcal{Q}_{\mathrm{gl}}^{j}}$ is a SOS2,

$q_{\mathrm{o}}^{j} \leq q_{\mathrm{o}}^{\max }$

\section{Flowlines}

For each flowline $f \in \mathcal{L}$ :

$q_{\mathrm{liq}}^{f}=\sum_{j \in \mathcal{W}_{f}} q_{\mathrm{w}}^{j}+q_{o}^{j}$,

$q_{\mathrm{g}}^{f}=\sum_{j \in \mathcal{W}_{f}} q_{\mathrm{g}}^{j}+q_{\mathrm{gl}}^{j}$

$q_{\mathrm{w}}^{f}=\sum_{j \in \mathcal{W}_{f}} q_{\mathrm{w}}^{j}$

The pressure drop across pipeline $f$ is given by

$p_{\text {out }}^{f}-p_{\text {in }}^{f}=\Delta p_{f}$

where $\Delta p_{f}$ is approximated from a SOS2 piecewise linear model:

$$
\begin{aligned}
\Delta p_{f}= & \sum_{q_{l} \in \mathcal{Q}_{\text {liq }}^{f}} \Omega_{q_{l}, w, g, p}^{f} \cdot \widehat{\Delta p}_{f}\left(q_{l}, w, g, p\right), \\
w & \in \mathcal{F}_{\text {wc }}^{f} \\
& g \in \mathcal{F}_{\text {gor }}^{f} \\
& p \in \mathcal{P}_{\text {in }}^{f}
\end{aligned}
$$

$$
\begin{aligned}
q_{\mathrm{liq}}^{f}= & \sum_{q_{l} \in \mathcal{Q}_{\mathrm{liq}}^{f}} \Omega_{q_{l}, w, g, p}^{f} \cdot q_{l}, \\
& w \in \mathcal{F}_{\mathrm{wc}}^{f} \\
& g \in \mathcal{F}_{\text {gor }}^{f} \\
& p \in \mathcal{P}_{\text {in }}^{f}
\end{aligned}
$$

$$
\begin{aligned}
q_{\mathrm{w}}^{f}= & \sum_{q_{l} \in \mathcal{Q}_{\mathrm{liq}}^{f}} \Omega_{q_{l}, w, g, p}^{f} \cdot q_{l} \cdot w, \\
& w \in \mathcal{F}_{\mathrm{wc}}^{f} \\
& g \in \mathcal{F}_{\text {gor }}^{f} \\
& p \in \mathcal{P}_{\text {in }}^{f}
\end{aligned}
$$




$$
\begin{aligned}
q_{\mathrm{g}}^{f}= & \sum_{\substack{q_{l} \\
w}} \mathcal{Q}_{\mathrm{liq}}^{f} \Omega_{q_{l}, w, g, p}^{f} \cdot q_{l} \cdot(1-w) \cdot g, \\
& =\mathcal{F}_{\mathrm{wc}}^{f} \\
& g \in \mathcal{F}_{\mathrm{gor}}^{f} \\
& p \in \mathcal{P}_{\text {in }}^{f}
\end{aligned}
$$

$$
\begin{aligned}
p_{\text {in }}^{f}= & \sum_{q_{l} \in \mathcal{Q}_{\mathrm{liq}}^{f}} \Omega_{q_{l}, w, g, p}^{f} \cdot p, \\
& w \in \mathcal{F}_{\mathrm{wc}}^{f} \\
& g \in \mathcal{F}_{\mathrm{gor}}^{f} \\
& p \in \mathcal{P}_{\text {in }}^{f}
\end{aligned}
$$$$
\sum_{q_{l} \in \mathcal{Q}_{\mathrm{liq}}^{f}} \Omega_{q_{l}, w, g, p}^{f}=1 .
$$$$
w \in \mathcal{F}_{\mathrm{wc}}^{f}
$$$$
g \in \mathcal{F}_{\text {gor }}^{f}
$$$$
p \in \mathcal{P}_{\text {in }}^{f}
$$

$\left(\phi_{w}^{f}\right)_{w \in \mathcal{F}_{\mathrm{wc}}^{f}}$ is a SOS2,

$\left(\psi_{g}^{f}\right)_{g \in \mathcal{F}_{\text {gor }}^{f}}$ is a SOS2,

$\left(\mu_{p}^{f}\right)_{p \in \mathcal{P}_{\text {in }}^{f}}$ is a SOS2.

For all $q_{l} \in \mathcal{Q}_{\mathrm{liq}}^{f}, w \in \mathcal{F}_{\mathrm{wc}}^{f}, g \in \mathcal{F}_{\mathrm{gor}}^{f}, p \in \mathcal{P}_{\mathrm{in}}^{f}$ :

$$
\Omega_{q_{l}, w, g, p}^{f} \geq 0
$$

We define the sets $\lambda_{q_{l}}^{f}, \phi_{w}^{f} ; \psi_{g}^{f}$, and $\mu_{p}^{f}$, as follows:

$$
\begin{aligned}
& \forall q_{l} \in \mathcal{Q}_{\mathrm{liq}}^{f}, \quad \lambda_{q_{l}}^{f}= \sum_{w \in \mathcal{F}_{\mathrm{wc}}^{f}} \Omega_{q_{l}, w, g, p}^{f}, \\
& g \in \mathcal{F}_{\mathrm{gor}}^{f} \\
& p \in \mathcal{P}_{\text {in }}^{f}
\end{aligned}
$$

$$
\begin{aligned}
\forall w \in \mathcal{F}_{\mathrm{wc}}^{f}, \quad \phi_{w}^{f}= & \sum_{\substack{q_{l} \in \mathcal{Q}_{\mathrm{liq}}^{f} \\
g \in \mathcal{F}_{\mathrm{gor}}^{f}}} \Omega_{q_{l}, w, g, p}^{f}, \\
& p \in \mathcal{P}_{\mathrm{in}}^{f}
\end{aligned}
$$

\section{Flow equilibrium}

\section{Well cocking}

Chocking is modeled as a simple pressure drop $\Delta p_{\text {choke }}^{j}$ across the choke. Therefore, choking imposes the following constraint:

$\forall j \in \mathcal{W}_{f}, \quad p_{\text {wh }}^{j} \geq p_{\text {in }}^{f}$.

\section{Pipeline junction}

At the junction of two pipelines $f_{1}$ and $f_{2}$ (assuming $f 1$ is producing into $f_{2}$ ), flow equilibrium is modeled as follows:

$p_{\text {out }}^{f_{1}}=p_{\text {in }}^{f_{2}}$.

For flowline $f_{2}$, Eq. (34), (35), and (36) are replaced by:

$q_{\mathrm{liq}}^{f_{2}}=q_{\mathrm{liq}}^{f_{1}}+\sum_{j \in \mathcal{W}_{f_{2}}} q_{\mathrm{w}}^{j}+q_{o}^{j}$,

$q_{\mathrm{g}}^{f_{2}}=q_{\mathrm{g}}^{f_{1}}+\sum_{j \in W_{f_{2}}} q_{\mathrm{g}}^{j}+q_{\mathrm{gl}}^{j}$,

$$
\begin{aligned}
& \forall g \in \mathcal{F}_{\text {gor }}^{f}, \quad \psi_{g}^{f}= \sum_{q_{l} \in \mathcal{Q}_{\mathrm{liq}}^{f}} \Omega_{q_{l}, w, g, p}^{f}, \\
& w \in \mathcal{F}_{\mathrm{wc}}^{f} \\
& p \in \mathcal{P}_{\mathrm{in}}^{f}
\end{aligned}
$$

$$
\begin{aligned}
& \forall p \in \mathcal{P}_{\text {in }}^{f}, \quad \mu_{p}^{f}= \sum_{q_{l} \in \mathcal{Q}_{\mathrm{liq}}^{f}} \Omega_{q_{l}, w, g, p}^{f}, \\
& w \in \mathcal{F}_{\mathrm{wc}}^{f} \\
& \\
& g \in \mathcal{F}_{\mathrm{gor}}^{f}
\end{aligned}
$$

$q_{\mathrm{w}}^{f_{2}}=q_{\mathrm{w}}^{f_{1}}+\sum_{j \in \mathcal{W}_{f_{2}}} q_{\mathrm{w}}^{j}$,

\section{Production separator}

In the special case where flowline $f$ is producing into the production separator, then the flow equilibrium is modeled as follows:

$p_{\text {out }}^{f}=p_{\text {sep }}$.

\section{Notations used in the optimization}

This section presents all notations used in the optimization formulation. 


\section{References}

Al-Shaalan TM, Dogru A, Fung L (2002) Coupling the reservoir simulator powers with the surface facilities' network simulator pipesoft. Saudi Aramco J Technol Fall 2002:13-21

Ali SMF, Nielsen RF (1970) The material balance approach vs reservoir simulation as an aid to understanding reservoir mechanics. SPE-3080, presented at the fall meeting of the Society of Petroleum Engineers of AIME, 4-7 October, Houston, Texas, USA, Society of Petroleum Engineers. https://doi.org/102118/3080-MS

Barroux CC, Duchet-Suchaux P, Samier P, de France) RNG (2000) Linking reservoir and surface simulators: how to improve the coupled solutions. SPE-65159-MS, presented at the SPE European petroleum conference, 24-25 October, Paris, France, Society of Petroleum Engineers. https://doi.org/10.2118/65159-MS

Codas A, Camponogara E (2012) Mixed-integer linear optimization for optimal lift-gas allocation with well-separator routing. Eur J Oper Res 217(1):222-231. https://doi.org/10.1016/j.ejor.2011.08.027

Codas A, Campos S, Camponogara E, Gunnerud V, Sunjerga S (2012) Integrated production optimization of oil fields with pressure and routing constraints: the Urucu field. Comput Chem Eng 46:178189. https://doi.org/10.1016/j.compchemeng.2012.06.016

Dempsey JR, Patterson JK, Coats KH, Brill JP (1971) An efficient method for evaluating gas field gathering system design. J Pet Technol 23(9):1067-1073. https://doi.org/10.2118/3161-PA

Fang WY, Lo KK (1996) A generalized well management scheme for reservoir simulation. SPE Reserv Eng 1(2):116-120. https://doi. org/10.2118/29124-PA

Haldorsen HH (1996) Choosing between rocks, hard places and a lot more: the economic interface. In: Dore AG, Sinding-Larsen R (eds) Quantification and prediction of hydrocarbon resources. Norwegian Petroleum Society Special Publications, vol 6. Elsevier, Amsterdam, pp 291-312. https://doi.org/10.1016/S0928 -8937(07)80025-7

Hepguler G, Barua S, Bard W (1997) Integration of a field surface and production network with a reservoir simulator. SPE Comput Appl 9(3):88-92. https://doi.org/10.2118/38937-PA

Hoffmann A, Stanko M (2017) Short-term model-based production optimization of a surface production network with electric submersible pumps using piecewise-linear functions. J Pet Sci Eng 158:570-584. https://doi.org/10.1016/j.petrol.2017.08.063

Hoffmann A, Astutik W, Rasmussen F, Whitson CH (2016) Diluent injection optimization for a heavy oil field. SPE-184119-MS, presented at the SPE heavy oil conference and exhibition, 6-8 December, Kuwait City, Kuwait, Society of Petroleum Engineers. https://doi.org/10.2118/184119-MS

Hulse EO, Camponogara E (2017) Robust formulations for production optimization of satellite oil wells. Eng Optim 49(5):846-863

Jahn F, Cook M, Graham M (2008) Hydrocarbon exploration and production, developments in petroleum science. Elsevier, Amsterdam

Kosmidis VD, Perkins JD, Pistikopoulos EN (2004) Optimization of well oil rate allocations in petroleum fields. Ind Eng Chem Res 43(14):3513-3527. https://doi.org/10.1021/ie034171z

Silva TL, Camponogara E (2014) A computational analysis of multidimensional piecewise-linear models with applications to oil production optimization. Eur J Oper Res 232(3):630-642. https ://doi.org/10.1016/j.ejor.2013.07.040

Silva TL, Camponogara E, Teixeira AF, Sunjerga S (2015) Modeling of flow splitting for production optimization in offshore gas-lifted oil fields: simulation validation and applications. J Pet Sci Eng 128:86-97

Stanko M, Venstad JM (2016) Using combinatorics to compute fluid routing alternatives in a hydrocarbon production network. J Pet Explor Prod Technol. https://doi.org/10.1007/s13202-016-0291-1

Valbuena E, Barrufet M, Killoug J (2015) Forecasting production performance in reservoir-network coupled systems with asphaltene modeling. SPE-174795, presented at the SPE Annual Technical Conference and Exhibition held in Houston, Texas, USA, 28-30 September, Society of Petroleum Engineers. https://doi. org/10.2118/174795-MS

Zapata VJ, Brummett WM, Osborne ME, Nispen DJV (2001) Advances in tightly coupled reservoir/ wellbore/surface-network simulation. SPE Reserv Eval Eng 4(2):114-120. https://doi. org/10.2118/71120-PA

Publisher's Note Springer Nature remains neutral with regard to jurisdictional claims in published maps and institutional affiliations. 